TAO, Vol. 16, No. 5, 1121-1132, December 2005

\title{
Organic Carbon Inferred Environmental Fluctuations during Late Quaternary, Southwestern Taiwan
}

\author{
Hung-Wei Chiang ${ }^{1}$ and Yue-Gau Chen ${ }^{1, *}$ \\ (Manuscript received 8 May 2005, in final form 14 September 2005)
}

\begin{abstract}
Organic carbon abundance and isotopic composition of sediments in a coastal plain are potentially used to indicate depositional environments and hinterland organic sources. Since Taiwan is located on the eastern margin of the Eurasian continent facing eastward to the Pacific, its geographical position is sensitive to interactions between the sea and land. Changes in the climate have a direct bearing on the costal environment and types of terrestrial plant species that inhabit it. In this study, we sampled two cores drilled from the coastal plain of southwestern Taiwan, and conducted concentration and isotopic analyses of organic carbon.

Compared with the generally accepted environmental evolution of Taiwan, our study shows the dominant marine organic source have brought on relatively stable carbon abundance and low level isotopic values for total organic carbon (TOC), whilst input from terrestrial sources attributed to arid-climate-induced $\mathrm{C}_{4}$ plant blooms make TOC content and $\delta^{13} \mathrm{C}$ value vary more widely. The lower parts of the cores indicate the entire study area was inundated by seawater as a result of the high sea-stand of MIS (marine isotope stage) 5. At Machouhou (MCH), the sedimentary environment became terrestrial in MIS 4, but returned to a shallow marine environment in MIS 3. The environment probably remained terrestrial at Tsungyeh (TY) during MIS $2 \& 3$; a period characterized in the cores as having high fluctuations in TOC with strong $\mathrm{C}_{4}$ plant signals. Subsequently both of these areas evolved into shallow marine environments after the beginning of the Holocene due to the world-wide postglacial transgression. Although the coastal environment and climate of southwestern Taiwan display characteristics consistent with the major trends in global change oc-
\end{abstract}

${ }^{1}$ Department of Geoscience, National Taiwan University, Taipei, Taiwan, ROC

* Corresponding author address. Prof. Yue-Gau Chen, Department of Geoscience, National Taiwan University, Taipei, Taiwan, ROC; E-mail:ygchen@ntu.edu.tw 


\title{
curring during the late Pleistocene, they also exhibit subtler features influ- enced by local geography and neotectonics.
}

\author{
(Key words: Organic carbon; $\mathbf{C}_{3}$ and $\mathbf{C}_{4}$ plant; $\delta^{13} \mathrm{C}$; late Quaternary; \\ Coastal environment)
}

\section{INTRODUCTION}

Taiwan is located at the junction point of an arc-continental collision between the Philippine Sea and Eurasian plates (Fig. 1a), where monsoon interactions are considered of great importance in controlling the regional climate. Due to frequent climate change during the late Quaternary, the coastal area of western Taiwan was repeatedly inundated with seawater as sea levels changed; and this history has been preserved in the sedimentary sequence of the region. According to previous studies (Hsieh and Chen 1999), the sedimentary environment of the coastal plain of Taiwan was mainly controlled by global sea-level changes. However, tectonically induced influences such as crustal movements and fluctuations in sediment supply would supposedly have manifested in Taiwan, hence we purposely collected core samples of high resolution, i.e., every 3 to $4 \mathrm{~m}$, to unravel the more subtle environmental changes which may have occurred in the region.

Carbon consists of so-called organic and inorganic carbon depending on its source in the carbon cycle i.e., organisms or carbonates. The type of sedimentary environment that captures carbon has a direct impact on the patterns of organic and inorganic carbon abundance in such sediments. Besides abundance, organic carbon in sediments can preserve syn-depositional signals (isotopes), which are of use in source identification (Arthur et al. 1988; Müller and Voss 1999). The isotopic composition of organic carbon is hence widely used as a proxy to determine the different organic sources of carbon, which in turn can reflect the sedimentary environment that captured the carbon and vegetation changes that might have occurred at the time (Hatté et al. 1998; Minoura et al. 1997; Mora and Pratt 2002; Tenzer et al. 1999; Schubert and Calvert 2001). In addition to organic matter from reworked sediments, two major sources are believed to provide the organic carbon buried in coastal sediments. These are terrestrial plants and marine organisms both of which can be distinguished by their characteristic carbon isotope values (Deines 1980). Terrestrial $\mathrm{C}_{3}$ and $\mathrm{C}_{4}$ plants using different photosynthetic pathways give rise to specific $\delta^{13} \mathrm{C}$ values $\left(\mathrm{C}_{3}:-26 \sim-28 \% ; \mathrm{C}_{4}:-12 \sim-14 \%\right.$ ), due to different isotopic fractionations (Deines 1980; Farquher 1980; O'Leary 1981, 1988). $\mathrm{C}_{4}$ plants flourish in relatively high temperatures, low humidity (or rainfall) and $p \mathrm{CO}_{2}$ conditions such as those occurring during glacial times in the geological past (Jolly and Haxeltine 1997), while $\mathrm{C}_{3}$ plants survive well in cool, humid, and high $p \mathrm{CO}_{2}$ conditions. The $\delta^{13} \mathrm{C}$ values of organic matter in marine sediments vary widely (Deines 1980); however, Hsieh and Chen (1999) and Hsieh et al. (2000) pointed out the values are relatively constant in local shallow marine environments in Taiwan $(-21 \sim-24 \%$ ). Additionally, Hsieh and Chen (1999) showed that the samples from field outcrops of Pleistocene and Pliocene formations have a $\delta^{13} \mathrm{C}$ value of $-25 \sim-26 \%$. In summary, the $\delta^{13} \mathrm{C}$ signature may be used not only as an indicator of land 
vegetation but also as a good proxy of climate-induced coastal environment changes.

Previous studies in Taiwan have shown that a late Quaternary sedimentary sequence, more than 300 meters thick, overlies the Tertiary basement at places where the subsidence rate is relatively high, such as on Chianan Plain (Figs. 1b, c). Based on luminescence ages published by Chen et al. (2003), the studied cores contain a historical record of approximately one

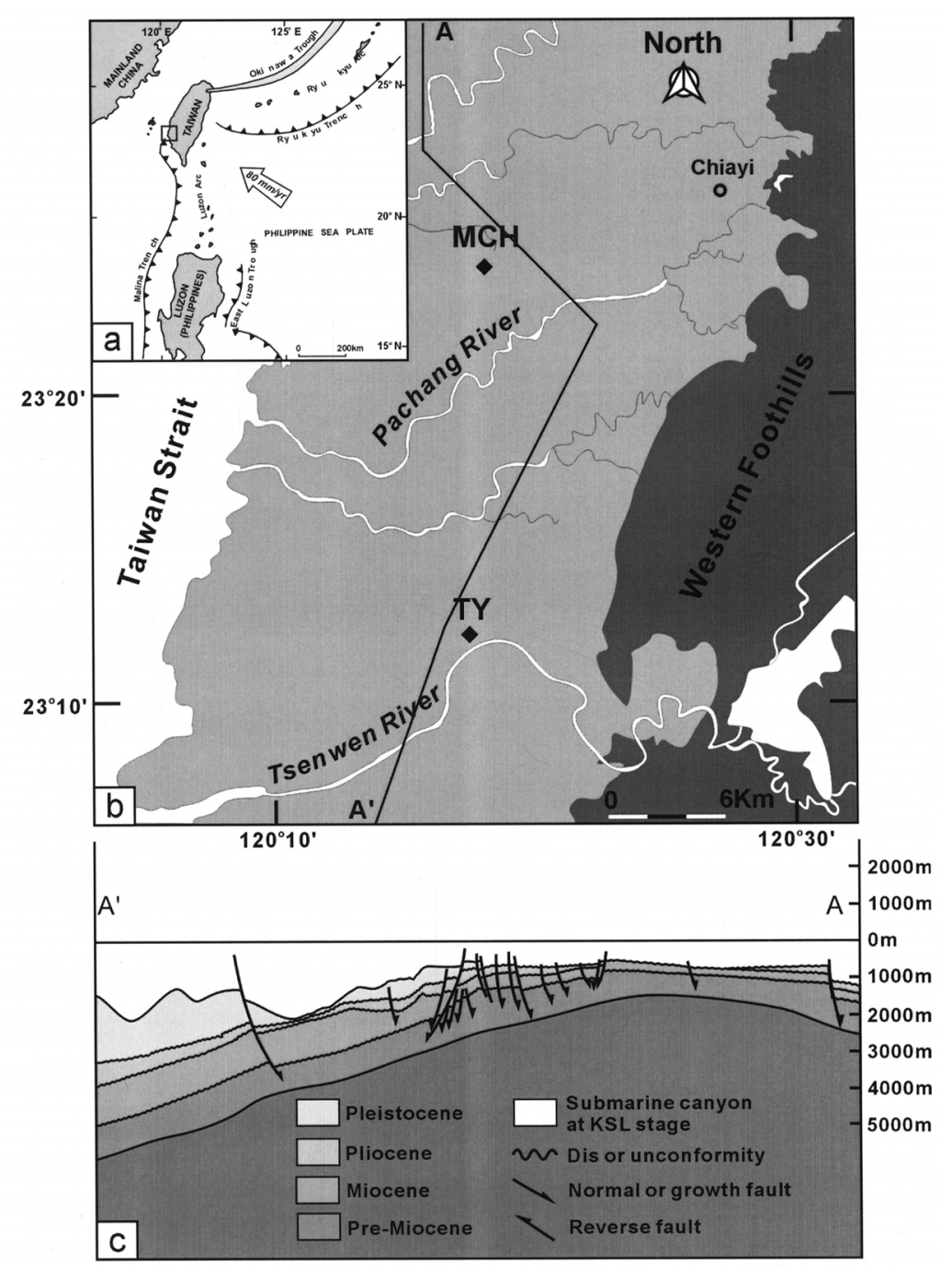

Fig. 1. (a) Maps of tectonic environments surrounding Taiwan, (b) core-drilling sites, MCH and TY, and (c) subsurface geology (adapted from Liou and Hsu, 1988). According to the subsurface geology of A to A', sedimentary sequence of late Quaternary over 300 meters overlies the Tertiary basement. 
hundred thousand years, and can provide high-resolution sedimentary information from at least MIS 5. By determining total organic-carbon abundance (TOC) and the stable carbonisotopic composition $\left(\delta^{13} \mathrm{C}\right)$ of core sediments, this study aims to discover more detail regarding environmental evolution during the late Pleistocene in the southwestern coastal area of Taiwan.

\section{SAMPLING SITES AND MATERIALS}

Two cores from Tsungyeh (TY) and Machouhou (MCH) were drilled in the Chianan plain by the Central Geological Survey (Fig. 1b), both with a length of ca. $250 \mathrm{~m}$. To obtain high-resolution results, the samples were collected at intervals of $3-4 \mathrm{~m}$. Based on published radiocarbon and optically stimulated luminescence (OSL) ages (Chen et al. 2003), the longterm $2.0 \mathrm{~mm} \mathrm{yr}^{-1}$ subsidence rate at TY is nearly the same as the short-term rate for the Holocene, indicating a stable rate of tectonic activity since the late Pleistocene. However, an estimated smaller subsidence rate obtained at $\mathrm{MCH}$ is around $1.6 \mathrm{~mm} \mathrm{yr}^{-1}$, which may have been caused by local neotectonics (Fig. 1c) (Liou and Hsu 1988). We, therefore, expected the record of sedimentary history at $\mathrm{MCH}$ to be of lower resolution but longer than that of TY. Additionally previous pollen studies (Tsan 1999) have shown that the TY core can be divided into 5 climatic zones: Zones $1 \& 2$ indicate a warm-humid climate; Zones $3 \& 4$, the mainly dry and cold period; Zone 5, the warmest and most humid stage.

\section{METHODOLOGY}

Each sample was dried at $60^{\circ} \mathrm{C}$ overnight, and then dispersed and sieved with only the fraction of grain size smaller than 230 mesh retained. Part of each sample was separated for total carbon (TC) determination. Other parts, thereafter, were rinsed with $2 \mathrm{~N} \mathrm{HCl}$ to remove carbonates. The solution was then centrifuged and decanted. The residue was collected on Whatman GF/C glass-fiber filter-paper and then washed with 2 liters of deionized water until the wash water became neutral. The filter-paper and sample was again dried at $60^{\circ} \mathrm{C}$. Each of the dried samples was finally well mixed and separated into two aliquots for later TOC and $\delta^{13} \mathrm{C}$ analysis.

TC and TOC were measured using an elemental analyzer (EA1110, ThermoQuest). Total inorganic carbon (TIC) was obtained by subtracting TOC from TC. For determination of isotopic composition, two methods were individually adopted to half samples. In the first, the dried, powdered, and decalcified sediment samples were mixed with copper wire, cupric oxide, and thin silver ribbon in a quartz tube of $10 \mathrm{~mm}$ OD. The tubes were sealed in a vacuum and then heated in a furnace at $860^{\circ} \mathrm{C}$ for over $4 \mathrm{~h}$. To ensure high recovery, we used a cooling rate lower than $1^{\circ} \mathrm{C} / \mathrm{min}$ from 860 to $600^{\circ} \mathrm{C}$. The generated $\mathrm{CO}_{2}$ gases were extracted in a vacuum system after the tubes returned to room temperature. Isotope values were determined by gas ratio mass spectrometer (Finnigan Delta Plus) at the Department of Geosciences, National Taiwan University. The second method to determine isotopic composition involved automati- 
cally combusting the samples by utilizing an on-line analytical system of EA + ConFlow + Mass Spectrometer. All of the isotope ratios are reported in per mil (\%) relative to PDB. System error is estimated to be $\pm 0.1 \%$ from some duplicate analyses, and the differences between the two methods is about 0.42 , estimated from $10 \%$ remeasured samples.

\section{TIME SERIES}

Before starting to discuss the environment and land vegetation changes, we have to establish the time series for both of the cores (Figs. 2, 3). For TY, based on combined sedimentary sequences and published age data, the depth of $88 \mathrm{~m}$ is probably the lower boundary of MIS 1 strata; $230 \mathrm{~m}$ represents the boundary between MIS 4 and 5. However, it is difficult to define the boundaries of MIS $2 \sim 3$ and MIS $3 \sim 4$ without clear and reliable characteristics. For $\mathrm{MCH}$, the boundary of MIS $1 \sim 2$ is located at the depth of $50 \mathrm{~m}$, and the boundary of MIS $4 \sim 5$ is at $150 \mathrm{~m}$, consistent with the less subsidence rate discussed above. The boundaries of MIS $2 \sim 3$ and MIS $3 \sim 4$ are also difficult to define. Hence, we interpolated the depths of MIS $2 \sim 3$ and MIS $3 \sim 4$ between MIS $1 \sim 2$ and MIS $4 \sim 5$ by assuming a stable long-term subsidence rate in both cores. The supposed boundaries are compatible with the records of sedimentary sequences, indicating the established time series are reasonable.

\section{RESULTS}

\subsection{TY Core}

Two distinct schematic types of the $\delta^{13} \mathrm{C}$ distribution pattern can be identified: relatively steady and widely fluctuating. The corresponding TOC and TIC values are also distinguishable for each type, although both of them are mostly lower than $1 \%$ (Fig. 2). TYPE-I (shaded in Fig. 2) is found in the intervals at depths of $0 \sim 65 \mathrm{~m}$ and $180 \sim 250 \mathrm{~m}$, where the individual percentages of TOC and TIC in sediments are relatively equal in these periods and $\delta^{13} \mathrm{C}$ shows a steady value of $-23 \sim-24 \%$, except at depths of $56 \sim 61 \mathrm{~m}$. TYPE-II (blanked in Fig. 2) is distributed in $65 \sim 180 \mathrm{~m}$, where TIC values are very close to zero with a small number of drastic peaks while TOC and $\delta^{13} \mathrm{C}$ values fluctuate widely.

\subsection{MCH Core}

Both of the characteristic schematic types identified in the TY core mentioned above can also be recognized in core MCH (Fig. 3). Three sections, i.e., $0 \sim 25 \mathrm{~m}, 75 \sim 130 \mathrm{~m}$ and $150 \sim 240 \mathrm{~m}$, show relatively small variations in TIC and TOC, where the $\delta^{13} \mathrm{C}$ values are low and steady (shaded in Fig. 3). The rest of the core is characterized by fluctuating TOC and $\delta^{13} \mathrm{C}$ values, and the corresponding TIC values sometimes approximate to zero (blanked in Fig. 3). Although the maxima $\delta^{13} \mathrm{C}$ values are as high as nearly $-13 \%$, much heavier than that of TY and similar to typical terrestrial $\mathrm{C}_{4}$ plants, we, however, think it is just a locally abnormal fortuity instead of an environment solely populated with $\mathrm{C}_{4}$ plants. 

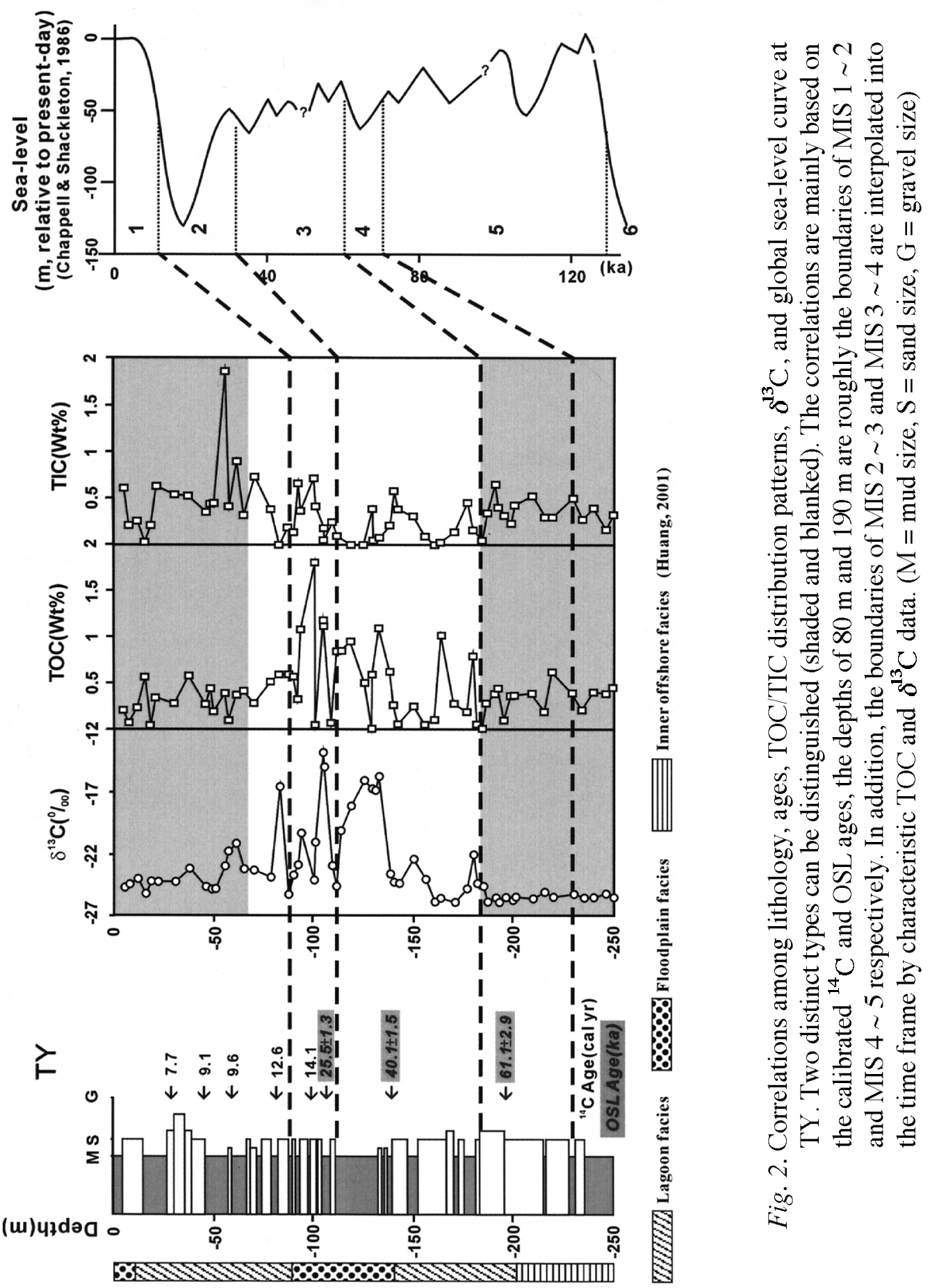

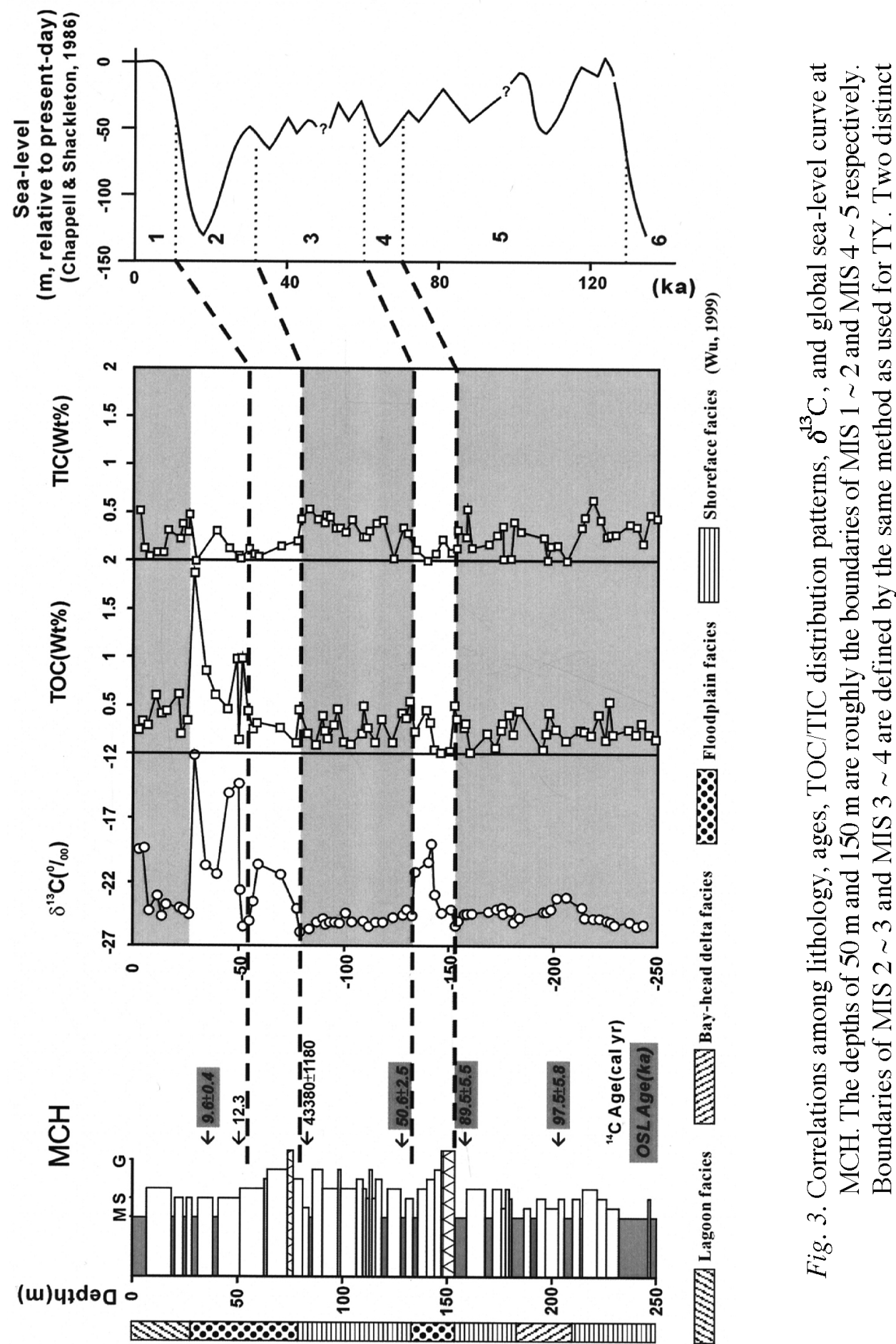

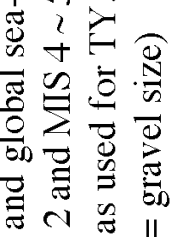

j<

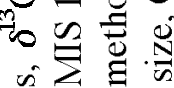

岁过

象施

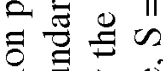

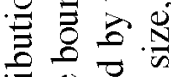

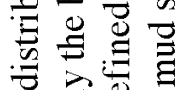

U 긍

它它之

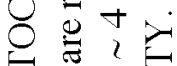

in $m \equiv$

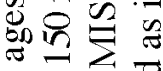

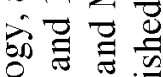

흥

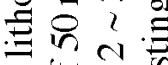

60,

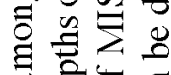

के 항

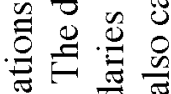

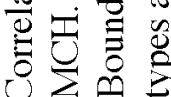

$\dot{m}$

$\dot{x}$ 


\section{DISCUSSIONS}

\subsection{The Relationship between $\delta^{13} \mathrm{C}$, TOC-TIC and Environmental Change}

Governed principally by the two major sources of organic matter in coastal sediments, carbon isotope values and TOC vs. TIC distribution patterns of both cores can be divided into two types: terrestrial plants and marine organisms. The generally accepted environmental evolution of the Taiwan region from MIS 2 to the present has been previously reported (Chen 1993; Liew et al. 1998) and is summarized below. In MIS 2 the climate was arid with a much lower sea level than today, meaning the western coastal area of Taiwan was a terrestrial fluvial environment. Afterwards, toward the beginning of MIS 1 a rapid transgression occurred that turned most of the coastal plain area into a shallow marine environment. In the late Holocene, however, the coastal area again returned to a terrestrial environment due to the rapid sediment supply associated with mountain building. According to the time series established in this study, depths of $88 \sim 110 \mathrm{~m}$ in TY and 55 75 $\mathrm{m}$ in MCH can be correlated to MIS 2. In this arid, low-stand period terrestrial plants are the major organic source, though their occupied extent in the coastal area varies with time due to varying hinterland precipitations. As a consequence, chemical proxies for the organic matter of the terrestrial-influenced environment are characterized by nearly zero TIC and fluctuating TOC \& $\delta^{13} \mathrm{C}$ values. These characteristics are controlled by temporal changes in stream energy, extremely small carbonate fraction, and prevailing upland vegetation types. Such a terrestrial environment did not end until the beginning of MIS 1 and continued for an extended period of time in some regions because of geographical variations. At depths of $65 \sim 88 \mathrm{~m}$ in TY and $25 \sim 55 \mathrm{~m}$ in $\mathrm{MCH}$, our proxies show a transition from a terrestrial to marine environment. When the transgression maximum was approached, marine organic source became dominant, such as $0 \sim 65 \mathrm{~m}$ in TY and $5 \sim 25 \mathrm{~m}$ in $\mathrm{MCH}$. The $\delta^{13} \mathrm{C}$ steadied reflecting a value of phytoplankton, -21 to $-24 \%$ (Hsieh and Chen 1999; Hsieh et al. 2000). Accordingly, TOC and TIC values are also relatively steady. Moreover, the topmost part of the $\mathrm{MCH}$ core is again characterized by fluctuating $\delta^{13} \mathrm{C}$ values, undulating TOC and near zero TIC, likely reflecting a local event of limited extent, while this pattern is not obvious in the TY core. Applying the same criteria discussed above to older sediments, we found that depths of $110 \sim 180 \mathrm{~m}$ in TY and $130 \sim 150 \mathrm{~m}$ in MCH environments were probably terrestrial, which correlates to MIS 3 for TY and MIS 4 for MCH respectively. This inference seems reasonable judging by the global sea-level curve (Figs. 2, 3). The bottom parts of the cores (i.e., depths of $180 \sim 250 \mathrm{~m}$ in TY, and $150 \sim 250 \mathrm{~m}$ in $\mathrm{MCH}$ ) show marine environments inferred by the combined chemical proxies. In summary, TOC, TIC value, and $\delta^{13} \mathrm{C}$ signatures can be used as good proxies of the coastal environmental changes in western Taiwan due to the characteristics of land vegetation and marine sources.

\subsection{Major Arid Periods during the Late Pleistocene}

As discussed above, the interval of widely varying $\delta^{13} \mathrm{C}$ values (ca. $-12 \% \sim-25 \%$ ) and TOC represents the time when terrestrial plant material was the main source of preserved organic matter. As such, the different proportions of $\mathrm{C}_{3} \& \mathrm{C}_{4}$ biomass supposedly govern the gross $\delta^{13} \mathrm{C}$ of TOC. However, an absolute proportion cannot be simply obtained by converting 
the $\delta^{13} \mathrm{C}$ values to a two-end-member mixing model because of the indistinguishable $\delta^{13} \mathrm{C}$ values among $\mathrm{C}_{3}$ plants, phytoplankton, and organic matter preserved in reworked sediments. Arid terrestrial plants became important from late in MIS 3 in TY and from the beginning of MIS 2 in MCH. For both cores $\mathrm{C}_{4}$ plant signals became obscure when going into the Holocene due to the fast transgression. This echoes previous study results that the arid climate in MIS 2 had an impressive influence on Taiwan (Wei 1997; Wei et al. 2003). This chemical signal is consistent with another study, which presented a grass blooming event during the same time period due to weaker summer and stronger winter monsoons (Liew et al. 1998). Such a phenomenon has also been reported in neighboring areas, especially the continental shelves of eastern Asia (Sun and Li 1999; Sun et al. 2003). Although MIS 2 is a worldwide ice age, a particularly severe period of aridity appears to have affected high latitudinal areas of eastern Asia. We would like to address one more geographic cause that may enhance this glacial aridity in Taiwan. As we know, MIS 2 came with a very low sea level, ca. $120 \sim 130 \mathrm{~m}$ relative to the present day. The modern Taiwan Strait has an average depth of only ca. 50 60 $\mathrm{m}$ and the sea floor must have been exposed during glacial time. The western coastline of Taiwan would have disappeared and the nearest sea would have been to on Taiwan's east coast (Liew et al. 1998), hence, precipitation on the western coastal plain would have presumably decreased due to less moisture coming from the modern Taiwan Strait and the Asian southwestern summer monsoon. Furthermore, the sea-land configuration of southeastern Asia changed a lot during glacial times, making the South China Sea an "interior sea". Consequently, the drought of MIS 2 in western Taiwan was not only in response to a worldwide cold climate, but also enhanced by local and regional geographic effects.

\subsection{The Differences between Inferred Paleoenvironments at TY \& MCH}

Although the major climatic events, e.g., transgressions of MIS 1 and 5, and the regression of MIS 2, seem correlative between these two studied cores, the local responses are not exactly contemporary or of the same amplitude. In TY, $\delta^{13} \mathrm{C}$ values fluctuate from the beginning of MIS 3 to the mid-Holocene, indicating a longer $\mathrm{C}_{4}$ plant-dominated period than in $\mathrm{MCH}$ where $\mathrm{C}_{4}$ species domination occurred from the beginning of MIS 2. As discussed above, both of the TY and MCH areas underwent a marine transgression in MIS 5. Subsequently, the $\mathrm{MCH}$ area temporally emerged during MIS 4 before a second marine stage in MIS 3. In TY, the marine environment of MIS 5 for some reason persisted over MIS 4 before switching into a terrestrial environment in MIS 3. The delayed emergence of TY is probably due to the original water depth being deeper than in MCH during MIS 5. This is consistent with the general regression route from north to south in southwestern Taiwan during late Quaternary, derived by Chen (1993). On the other hand, the minor regression-transgression cycle during MIS $3 \sim 4$ in TY is probably sediment-supply related. Since TY is located along the major Tsengwen River, the water space is easily filled up by the sediments coming from Tsengwen River; by contrast, $\mathrm{MCH}$ has too lower sediment-supply to compete with the transgression in MIS 3. Hence, tectonic movement and geographic difference would play important roles in environmental evolution whilst the climate was in a relatively stable period.

At the beginning of MIS 1, TY and MCH were both still terrestrial environments, sug- 
gesting a lagged response of vegetation to climate change. This is probably also due to limited water in the west of Taiwan. It is worthwhile noting the high TIC signal in the early Holocene transgression at TY. Since TY is located close to the Tsengwen River, we interpret it as an estuarine environment in which TOC and $\delta^{13} \mathrm{C}$ is low, but relatively steady and with high TIC due to abundant shells. In summary, the sedimentary environments in southwestern Taiwan were influenced by not only global sea level but also local and regional geographic differences.

\section{CONCLUSIONS}

(1) Two distinct types can be distinguished from the TOC/TIC plus $\delta^{13} \mathrm{C}$ patterns in the two studied cores. TYPE I is characterized by relatively stable TOC and TIC. The corresponding $\delta^{13} \mathrm{C}$ values are also relatively steady with values of $-23 \sim-24 \%$. TYPE II is characterized by nearly zero TIC, but widely ranging values of TOC and $\delta^{13} \mathrm{C}$.

(2) The $\delta^{13} \mathrm{C}$ values of the sediments deposited during MIS 2 in the studied cores are heavier than the typical values of $\mathrm{C}_{3}$ plants and marine phytoplankton, indicating $\mathrm{C}_{4}$ plants flourished during that time period. This is consistent with the general conclusion given by other independent studies in other places of Taiwan.

(3) Both the TY and MCH areas were situated in a shallow-marine environment during MIS 5. Subsequently, the MCH area emerged in MIS 4 and was inundated by a second marine stage in MIS 3, while the TY area remained marine throughout MIS 4 but changed to a terrestrial environment in MIS 3. In the early stage of Holocene, both the studied areas were again transgressed, based on the characteristic $\delta^{13} \mathrm{C}$ value and abundances of organic matters.

(4) Our results also support the previously reported supposition that the summer monsoon became weaker in the glacial time, leading to arid climate. The dry and cold climate in the glacial times was probably amplified locally by drastic changes to the marine-land configuration due to the shallow water depth of the Taiwan Strait.

Acknowledgements This study was supported by National Science Council, R.O.C. under grant numbers: NSC 88-2116-M-002-015, NSC 89-2116-M-002-026 and NSC 89-2116-M002-048. We additionally thank Dr. Oung and an anonymous reviewer for their constructive suggestions.

\section{REFERENCES}

Arthur, M. A., W. E. Dean, and L. M. Pratt, 1988: Geochemical and climatic effects of increased marine organic carbon burial at the Cenomanian/Turonian boundary. Nature, 335, 714-717.

Chappel, J., and N. J. Shackleton, 1986: Oxygen isotopes and sea level.Nature, 324, 137-140.

Chen, Y. G., 1993: Sea-level change and neotectonics in southern part of Taiwan region since late Pleistocene. Ph.D. Dissertation, Dept. Geol., Nat. Taiwan Univ. 
Chen, Y. W., Y. G. Chen, A. S. Murray, and D. J. Lai, 2003: Luminescence dating of neotectonic activity on the southwestern coastal plain, Taiwan. Quat. Sci. Rev., 22, 1223-1229.

Deines, P., 1980: The isotopic composition of reduced organic carbon. In: Deines, P., (Ed.), Handbook of Environmental Isotope Geochemistry 1, Chichester: Amsterdam-OxfordNew York, 329-406.

Farquhar, G. D., 1980: Carbon isotope discrimination by plants: Effects of carbon dioxide concentration and temperature via the ratio of intercellular and atmospheric $\mathrm{CO}_{2}$ concentrations, In: Perman, G. I., (Ed.), Carbon Dioxide and Climate. Australian Research, Australian Acad. Sci., 105-110.

Hatté, C., M. Fontugne, D. Rousseau, P. Antoine, L. Zoller, N. Tisnerat-Laborde, and I. Bentaleb, 1998: $\delta^{13} \mathrm{C}$ variations of loess organic matter as a record of the vegetation response to climatic changes during the Weichselian. Geology, 26, 583-586.

Hsieh, C. C., and Y. G. Chen, 1999: Organic carbon isotopic analysis of sediments from southwestern Taiwan. Proc. 1999 An. Meet. Geol. Soc. China, 188-190.

Hsieh, H. L, W. Y. Kao, C. P. Chen, and P. J. Liu, 2000: Detrital flows through the feeding pathway of the oyster (Crassostrea gigas) in a tropical shallow lagoon: $\delta^{13} \mathrm{C}$ signals. Mar. Biol., 136, 677-684.

Huang, Y. T., 2001. Upper Quaternary sedimentary environments and sequence stratigraphy of the Tsengwen-his river Basin, Chianan Plain: A preliminary study. MS Thesis, Dept. Geol., Nat. Taiwan Univ.

Jolly, D., and A. Haxeltine, 1997: Effect of low glacial atmospheric $\mathrm{CO}_{2}$ on tropical African montane vegetation. Science, 276, 786-788.

Liew, P. M., C. M. Kuo, S. Y. Huang, and M. H. Tseng, 1998: Vegetation change and terrestrial carbon storage in eastern Asia during the Last Glacial Maximum as indicated by a new pollen record from central Taiwan. Global Planet. Change, 16-17, 85-94.

Liou, C. H., and C. Y. Hsu, 1988. Petroleum Exploration on the Southwestern plain of Taiwan. Petroleum Geol. Taiwan, 24, 18-36.

Minoura, K., K. Hoshino, T. Nakamura, and E. Wada, 1997. Late Pleistocene-Holocene paleoproductivity circulation in the Japan Sea: Jsea-level control on $\delta^{13} \mathrm{C}$ and $\delta^{15} \mathrm{~N}$ records of sediment organic material. Palaeogeogr., Palaeoclimatol., Palaeoecol., 135, 41-50.

Mora, G., and L. M. Pratt, 2002: Carbon isotopic evidence from paleosols for mixed $\mathrm{C}_{3} /$ $\mathrm{C}_{4}$ vegetation in the Bogota Basin, Colombia. Quat. Sci. Rev., 21, 985-995.

Müller, A., and M. Voss, 1999: The palaeoenvironments of coastal lagoons in the southern Baltic Sea, II. $\delta^{13} \mathrm{C}$ and $\delta^{15} \mathrm{~N}$ ratios of organic matter-sources and sediments. Palaeogeogr., Palaeoclimatol., Palaeoecol., 145, 17-32.

O'Leary, M. H., 1981: Carbon isotope fraction in plants. Phytochem., 20, 553-567.

O'Leary, M. H., 1988: Carbon isotope in photosynthesis. Fractionation techniques may reveal new aspects of carbon dynamics in plants. Biosci., 38, 228-336.

Schubert, C. J., and S. E. Calvert, 2001: Nitrogen and Carbon isotopic composition of marine and terrestrial organic matter in Arctic Ocean sediments: imolications for nutrient utilization and organic matter composition. Deep-Sea Res. I, 48, 789-810. 
Sun, X. G., and X. Li, 1999: A pollen record of the last $37 \mathrm{ka}$ in deep sea core 17940 from the northern slope of the South China Sea. Mar. Geol., 156, 227-244.

Sun, X. G., Y. L. Luo, F. Huang, J. Tian, and P. X. Wang, 2003: Deep-sea pollen from the South China Sea: Pleistocene indicators of East Asian monsoon. Mar. Geol., 201, $97-$ 118.

Tenzer, G. E., P. A. Meyers, J. A. Robbins, B. J. Eadie, N. R. Morehead, and M. B. Lansing, 1999: Sedimentary organic matter record of recent environmental changes in the St. Marys River ecosystem, Michigan-Ontario border. Organic Geochem., 30, 133-146.

Tsan, M. H., 1999: Research of Pollen Analysis and Stratigraphic Correlation. 1999 An. report Taiwan Groundwater Monitoring Network Project.

Wei, K., 1997: Thermoluminescence dating and organic carbon isotopic analysis of Wu-ku core, Taipei basin. MS Thesis, Dept. Geol., Nat. Taiwan Univ.

Wei, K. Y., Y. G. Chen, W. S. Chen, T. H. Lai, L. C. Chen, and L.Y. Fei, 2003: Climate change as the dominant control on the Last Glacial-Holocene $\delta^{13} \mathrm{C}$ variations of sedimentary organic carbon in the Lan-yang Plain, northeastern Taiwan. West. Pac. Earth Sci., 3, 57-68.

Wu, L. C., 1999: Research of Sedimentary Environment Analysis and Stratigraphic Correlation. 1999 An. report Taiwan Groundwater Monitoring Network Project. 